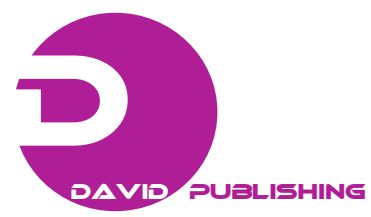

\title{
Determination of Functional Properties in Different Bangladeshi Fruits and Vegetables
}

\author{
M. Ashek-Un-Nabi Talukder, Ismail Hossain, M.M. Towhidul Islam, A.K.M. Mahbub Hasan and Hossain Uddin \\ Shekhar* \\ Department of Biochemistry and Molecular Biology, University of Dhaka, Dhaka 1000, Bangladesh \\ *Corresponding author's e-mail: hossainshekhar@yahoo.com
}

\begin{abstract}
Functional properties of a food depends on its capacity to act as a natural antioxidant, by scavenging lipid peroxides and also by the ability of the particular food component to bind fat and sugars efficiently. This study was undertaken to primarily screening out the functional properties of different Bangladeshi food. In this study, the antioxidant properties, total phenolic content, flavonoid and lipid peroxide contents of eight commonly used fruits and vegetables were examined. The ethanol extract of fruits including Amra (Hog Plum-Spondias dulcis), Jambura (Grape Fruit-Citrus maxima), Anaros (Pineapple-Ananas comosus), and Kamranga (Carambola-Averrhoa carambola), and the vegetables including Kolmi Shak (Water spinach-Ipomoea aquatica), Lal Shak (Red amaranth-Amaranthus gangeticus), Data Shak (Stem amaranth-Amaranthus lividus), Korola (Gourd-Momordica charantia) were examined. Both the fat and sugar binding capacity was found the highest in Anaros and lowest in Amra. Mortality rate of Brine shrimp (Artemia salina) nauplii in brine shrimp lethality bioassay at different concentration of fruits and vegetables extract showed that Jambura has the highest cytotoxic effect, killing $100 \%$ of the brine shrimp at a very low concentration $(0.01 \mathrm{mg} / \mathrm{mL})$, compared to the effect of positive control $(0.5 \mathrm{mg} / \mathrm{mL}$ of the Vincristine sulfate). In contrast, Lalshak showed the lowest ( $0 \%$ and $30 \%$ mortality) in vitro cytotoxic effect at both 0.01 and $0.1 \mathrm{mg} / \mathrm{mL}$ concentration. The Lal shak and Anaros extracts significantly reduced lipid peroxide (LPO) levels in the liver tissue homogenates. However, regarding the flavonoids content and phenolic content, Kamranga and Lal shak extracts showed the highest flavonoid contents, with mean values of 41.36 and $41.26 \mathrm{mg} / \mathrm{g}$, respectively. Anaros and Jambura showed the lowest flavonoid contents, with mean values of 0.5 and $9.3 \mathrm{mg} / \mathrm{g}$ respectively. The phenolic contents as expressed as gallic acid equivalent (GAE) mg/g extracts showed that Kolmi shak had the highest amount of phenolic compounds (59.33 $\pm 3.72 \mathrm{mg} / \mathrm{g}$ of GAE) and Anaros has the lowest phenolic contents $(11.00 \pm 1.33 \mathrm{mg} / \mathrm{g}$ of GAE). Therefore, these primary findings revealed enormous potentiality of commonly consumed Bangladeshi fruits and vegetables in health sectors.
\end{abstract}

Key words: Functional properties, phenolic content, flavonoid content, lipid peroxide, cytotoxicity, fruits and vegetables, Bangladesh. 